\title{
A gilded cage is still a cage: Cheshire West widens 'deprivation of liberty'
}

\author{
Catherine Penny and Tim Exworthy
}

\section{Summary}

The Supreme Court's recent judgment in Cheshire West has clarified, and broadened, the legal definition of deprivation of liberty, with the new definition reflecting the fact that human rights apply to everyone in the same way. The widely criticised Deprivation of Liberty Safeguards need to be replaced: recommendations for reform are set out.

\section{Declaration of interest}

None.
Catherine Penny (pictured) is a consultant forensic psychiatrist at West London Mental Health Trust and a visiting teacher in the Department of Forensic \& Neurodevelopmental Science at King's College London, Institute of Psychiatry, Psychology \& Neuroscience. Tim Exworthy is a consultant forensic psychiatrist and clinical director at St Andrew's Hospital, Northampton and a visiting senior lecturer in the same department. Both are interested in the law and its implications for people who have a mental disorder.

\section{Much needed clarity}

The European Convention on Human Rights gives states the responsibility to ensure that citizens are only deprived of their liberty in defined circumstances and in accordance with a procedure prescribed by law', with access to a speedy review by a court. The UK famously violated this right in the case of HL, who had autism and an intellectual disability and was admitted to a psychiatric hospital without the use of the Mental Health Act 1983 when he lacked capacity to consent to admission. ${ }^{1}$ Parliament responded by introducing the Deprivation of Liberty Safeguards (DoLS) ${ }^{2}$ in England and Wales, in force since April 2009. The use of the DoLS is triggered by a deprivation of liberty as understood by the European Court of Human Rights. But clinicians and lawyers, including those specialising in the subject, have not been able to agree on how to apply the Court's case law, ${ }^{3}$ and there has been widespread uncertainty and wide variation in practice. Assessors were supposed to consider a host of factors, with no clear thresholds.

The long-awaited Supreme Court judgment ${ }^{4}$ in the conjoined cases of Cheshire West and $P$ and $Q$ provides much needed clarity. If a person is 'under continuous supervision and control and ... not free to leave', they are deprived of their liberty. Factors previously considered relevant are now not relevant: the person's compliance or lack of objection; the relative normality of the placement; and the reason for it. There is still plenty to argue about. For example, does the 'and' mean that a person could not be free to leave and yet not be deprived of their liberty? This will have implications for some people subject to guardianship, a community treatment order or a conditional discharge under the Mental Health Act. 'Continuous supervision' is broader than continuous physical supervision, but exactly how much supervision is needed? Nonetheless, the whittling down to two key ingredients is a helpful step forward.

\section{A wider definition}

More controversial, however, is that the new definition is dramatically wider than the old interpretation. A minority of the Supreme Court judges thought that the European Court had not given clear enough guidance to support such a bold development in the law. The wider definition means that many more people than before are, in law, deprived of their liberty, and therefore formal procedures are needed to permit and to review this deprivation. Lady Hale, speaking for the majority, thought this was a good thing. ${ }^{4}$ She noted the risk of de-normalisation and stigma as a consequence of formalising deprivation of liberty for people living happy lives with the minimum restrictions necessary, but suggested that the vulnerability of people who lack capacity to decide on their living arrangements means we should 'err on the side of caution' in ensuring adequate scrutiny.

There is also an important principle at stake. Does liberty mean something different for a person who cannot take advantage of it? This had been the effect of the Court of Appeal's prior judgment in Cheshire West, where it was held that to determine whether someone was deprived of their liberty we should compare their living arrangements to those of someone else with similar characteristics, including any disabilities. In overturning this, Lady Hale was clear:

'[W] hat it means to be deprived of liberty must be the same for everyone, whether or not they have physical or mental disabilities. If it would be a deprivation of my liberty to be obliged to live in a particular place, subject to constant monitoring and control, only allowed out with close supervision, and unable to move away without permission even if such an opportunity became available, then it must also be a deprivation of the liberty of a disabled person. The fact that my living arrangements are comfortable, and indeed make my life as enjoyable as it could possibly be, should make no difference. A gilded cage is still a cage. ${ }^{4}$

She observed that equality in entitlement to human rights underpins the United Nations Convention on the Rights of Persons with Disabilities (CRPD), ${ }^{5}$ ratified by the UK in 2009, as well as the European Convention, and that 'the CRPD is recognised by the [court] as part of the international law context within which the guarantees of the European Convention are to be interpreted'. ${ }^{4}$

\section{Implications for mental health practice}

The immediate effect of Cheshire West is that many people will need to be assessed or reassessed to determine whether their circumstances fit the new definition. The Royal College of Psychiatrists has issued new guidance suggesting that all informal psychiatric in-patients be assessed, with psychiatrists considering how much supervision each patient is subject to and how staff would react if they tried to leave. ${ }^{6}$ If deprived of their liberty, a DoLS authorisation or a Mental Health Act assessment must be sought (the developing case law makes the choice between the two difficult in some instances). 
The Mental Health Act 1959 introduced informal admission to psychiatric hospital, with the hope of empowering and destigmatising patients. The pendulum is swinging back the other way, with increasing emphasis on patients' vulnerability. In 2012 in Rabone, ${ }^{7}$ the Supreme Court considered a voluntary patient de facto detained because she would have been detained if she had tried to leave, and so held that her European Convention right to life was engaged. Cheshire West narrows the potential for informality on psychiatric wards, with psychiatrists having to act in anticipation of a patient trying to leave if they think they would stop them. Although human rights litigation in mental health is still rare, psychiatrists are vulnerable as they try to balance the enduring imperatives to promote autonomy and to help the unwell.

\section{The need for reform}

The DoLS procedures are slow, expensive and ineffective. On 14 August 2013 the House of Commons Health Committee called for an urgent review, with an action plan for improvement, within 12 months. $^{8}$ On 13 March 2014 a House of Lords Select Committee described them as 'not fit for purpose,', as has the Mental Health Alliance. On 19 March 2014 Lady Hale, in Cheshire West, noted their 'bewildering complexity.4 Now many more people will fall within the scope of the DoLS, further increasing the burden on a system already struggling to cope. It looks like this will be the final nail in the coffin for the DoLS: at the government's request, the Law Commission is considering how deprivation of liberty should be authorised and supervised. It expects to publish recommendations for legislative reform in summer 2017.

In almost all countries, it is still possible to deprive a person of their liberty in hospital to enable treatment of their mental disorder even if they have capacity, as understood in the UK, to decide not to stay there. Many think that this is wrong and discriminatory, and it may be that the Mental Health Act 1983 is incompatible with the CRPD. ${ }^{10}$ The (widely admired) Mental Capacity Act 2005 could be developed to accommodate those whose deprivation of liberty has the purpose of enabling treatment for mental disorder (and who lack capacity to decide to be admitted and treated, and for whom this would be in their best interests). ${ }^{11}$ Academic and practitioner opinion appears to be moving in the direction of such a 'fusion law', and one is being developed in Northern Ireland. In England and Wales, however, there is strong political concern about the possibility of leaving at large people who have a mental disorder and are thought to pose a high risk to others.

\section{New safeguards informed by mental health law}

Although there is no sign in England and Wales of mental health law being informed by mental capacity law, the DoLS challenge provides an opportunity for mental capacity law to be informed by what mental health law does well. The mental health tribunal has evolved into a relatively quick, low-paperwork, professional, independent and effective review of detention at the place where the detention is occurring. The tribunal, with a more relevant professional where a consultant psychiatrist is not appropriate, could be developed for new deprivation of liberty safeguards.
The nearest relative could seek discharge using a procedure adapted from the Mental Health Act. A process similar to a Mental Health Act assessment could be used to authorise the initiation of a deprivation of liberty, with the equivalent of the Mental Health Act's section 4 and 5 procedures for detaining people for short periods while fuller assessments are arranged. A threshold duration, or anticipated duration, of deprivation of liberty before safeguards are needed may be helpful to ensure efficient access to care, for example in acute hospitals.

If new safeguards can provide effective reviews with sufficiently light bureaucracy, the widening of the definition of deprivation of liberty is to be welcomed. All who are under continuous supervision and control and not free to leave would benefit equally from real scrutiny, with minimal diversion of resources from other public services, including those providing the care arrangements involved. Reconciliation of procedures for those subject to mental health law and those subject to mental capacity law would be a step away from discrimination against mental health patients, even if, for now, they could still be detained when they had capacity to refuse admission. Such a move towards equality in access to the protection of the law would bring us closer to the aims of both the European Convention and the CRPD.

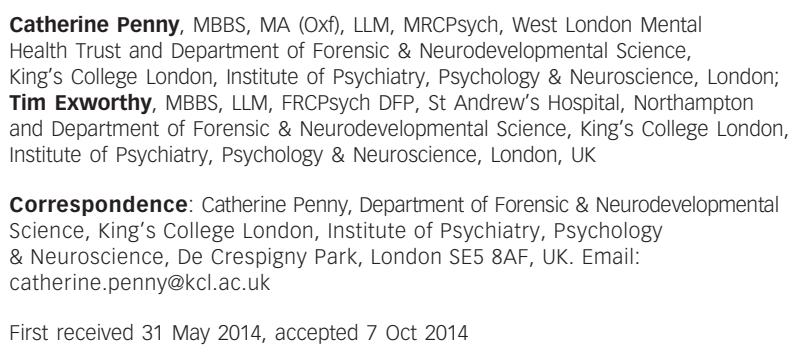

\section{References}

\section{HL V. UK [2004] ECHR 471.}

2 Ministry of Justice. Deprivation of Liberty Safeguards: Code of Practice to Supplement the Main Mental Capacity Act 2005 Code of Practice. Ministry of Justice, 2008.

3 Cairns R, Brown P, Grant-Peterkin H, Khondoker MR, Owen GS, Richardson G, et al. Judgements about deprivation of liberty made by various professionals: comparison study. Psychiatrist 2011; 35: 344-9.

\section{P V. Cheshire West and Chester Council \& Anor [2014] UKSC 19}

5 United Nations. Convention on the Rights of Persons with Disabilities. United Nations, 2006

6 Royal College of Psychiatrists. Mental Capacity Act - Update Following $P$ V Cheshire West and $P \& Q$ v. Surrey County Council Cases. Royal College of Psychiatrists, 2014 (http://www.rcpsych.ac.uk/policyandparliamentary/ mentalhealthlaw/mentalcapacityact.aspx).

7 Rabone \& Anor v Pennine Care NHS Foundation [2012] UKSC 2.

8 House of Commons Health Committee. Post-Legislative Scrutiny of the Mental Health Act 2007. House of Commons Health Committee, 2013.

9 House of Lords. Mental Capacity Act 2005: Post-Legislative Scrutiny. House of Lords, 2014.

10 Kelly BD. An end to psychiatric detention? Implications of the United Nations Convention on the Rights of Persons with Disabilities. Br J Psychiatry 2014; 204: $174-5$.

11 Dawson J, Szmukler G. Fusion of mental health and incapacity legislation. Br J Psychiatry 2006; 188: 504-9. 